\title{
REVIEW
}

\section{NIOX VERO: Individualized Asthma Management in Clinical Practice}

William D. Carroll

Received: June 2, 2016/ Published online: August 25, 2016

(c) The Author(s) 2016. This article is published with open access at Springerlink.com

\section{ABSTRACT}

As we move toward an era of precision medicine, novel biomarkers of disease will enable the identification and personalized treatment of new endotypes. In asthma, fractional exhaled nitric oxide (FeNO) serves as a surrogate marker of airway inflammation that often correlates with the presence of sputum eosinophils. The increase in FeNO is driven by an upregulation of inducible nitric oxide synthase (iNOS) by cytokines, which are released as a result of type- 2 airway inflammation. Scientific evidence supports using FeNO in routine clinical practice. In steroid-naive patients and in patients with mild asthma, FeNO levels decrease within days after corticosteroid treatment in a dose-dependent fashion and increase after steroid withdrawal. In difficult asthma, FeNO testing correlates with anti-inflammatory therapy compliance. Assessing adherence by FeNO testing can

Enhanced content To view enhanced content for this article go to http://www.medengine.com/Redeem/ F3E4F0607B4E106B.

W. D. Carroll ( $\square)$

Honorary Reader in Paediatric Respiratory Medicine, Keele University, Keele, UK

e-mail: will.carroll@nhs.net remove the confrontational aspect of questioning a patient about compliance and change the conversation to one of goal setting and ways to improve disease management. However, the most important aspect of incorporating FeNO in asthma management is the reduction in the risk of exacerbations. In a recent primary care study, reduction of exacerbation rates and improved symptom control without increasing overall inhaled corticosteroid (ICS) use were demonstrated when a FeNO-guided anti-inflammatory treatment algorithm was assessed and compared to the standard care. A truly personalized asthma management approach-showing reduction of exacerbation rates, overall use of ICS and neonatal hospitalizations-was demonstrated when FeNO testing was applied as part of the treatment algorithm that managed asthma during pregnancy. The aim of this article is to describe how FeNO and the NIOX VERO ${ }^{\circledR}$ analyzer can help to optimize diagnosis and treatment choices and to aid in the monitoring and improvement of clinical asthma outcomes in children and adults.

Keywords: Asthma; Endotype; NIOX VERO; Nitric oxide; Precision medicine 
INTRODUCTION: ASTHMA AND THE BEGINNING OF THE AGE OF PRECISION MEDICINE

Fifteen years ago, I was interviewed for a research fellowship. I think the two eminent professors leading the questioning were quietly enjoying themselves. Indeed, I was finding the experience quite jolly until I was asked a simple but insightful question. One of my interviewers (a respiratory pediatrician and superb researcher) looked me in the eye and asked, 'Are you a lumper or a splitter?' I fumbled for a few poorly chosen words and played for time by suggesting that it depended upon the context, but I did not give a particularly illuminating answer. I cannot honestly recall whether I finally decided whether I was, at heart, a lumper or a splitter. I did, however, get the job.

In the intervening years, I have considered this question deeply. Lumping has distinct advantages; in clinical settings, it allows guidelines to be constructed and applied. By 'lumping' a group of heterogeneous wheezing disorders of childhood together and applying a diagnostic label of 'asthma,' we have created a condition that is sufficiently common and important to enable research and develop an evidence base for treatment. Moreover, the simplistic approach of combining distinct phenotypes under a single term enables educational strategies to be adopted on a large scale. However, despite a wealth of evidence and the production of high-quality national and international guidelines, asthma control remains poor for most children. The gap between optimal outcomes for children with asthma in research settings and observed outcomes is undoubtedly multifactorial. However, the current strategy of lumping is not serving children with asthma or their families.
Guidelines currently suggest, for the most part, a 'one size fits all' approach with a step-up and step-down scheme that belies the inherent complexity and variation seen between individuals. Precision medicine is a new term that describes an approach for disease treatment and prevention that takes into account individual variability in genes, environment, and life choices. It facilitates the customization of health care tailored to each individual patient. It is particularly valuable for conditions such as asthma where there is considerable heterogeneity in phenotype. While precision medicine is evolving, and has had notable successes in the treatment of some types of cancer, it is not currently in use for most diseases, and asthma is no exception.

There are ranges of clinical and genetic factors, which are known to have some value in predicting the response to treatment in children with asthma. Thus, age, atopic status, bronchodilator responsiveness (BDR), ethnicity, gender, ethnicity and obesity have all been shown to predict responsiveness to inhaled corticosteroids (ICSs), leukotriene receptor antagonists (LTRA) and long-acting beta-2 agonists in selected populations of children (Table 1) [1-4].

These observations may be helpful in choosing 'what next?' when children present with persistent symptoms or recurrent exacerbations. However, these factors are often superseded by practical considerations in clinical practice. For instance, a young child who is uncooperative with the administration of inhaled medicines will be less likely to benefit from an inhaled treatment, and oral therapy may be more successful.

Biomarkers are likely to play an important role in the application of precision medicine to 
Table 1 Factors reported to predict differential response to inhaled corticosteroids and leukotriene receptor antagonists

\begin{tabular}{ll}
\hline Favors LTRA & Favors ICS \\
\hline Young age [3] & Poor lung function [3] \\
Atopy [3] & $\begin{array}{c}\text { High bronchodilator } \\
\text { reversibility [4] }\end{array}$ \\
$\begin{array}{c}\text { Elevated urinary } \\
\text { leukotrienes [3] }\end{array}$ & Black ethnicity [1] \\
& High FeNO [3] \\
\hline
\end{tabular}

ICS inhaled corticosteroids, FeNO fractional exhaled nitric oxide, LTRA leukotriene receptor antagonists

clinical practice. They have an established role in improving diagnosis and can accurately predict treatment response. A role probably exists for a range of markers including sputum eosinophils, exhaled breath condensate and the pattern of volatile organic compounds (VOCs). This article critically reviews the role of fractional exhaled nitric oxide (FeNO) and specifically the role of the NIOX VERO ${ }^{\circledR}$ in the application of precision medicine to children and adults with asthma.

\section{Compliance with Ethics Guidelines}

This article is based on previously conducted studies and does not involve any new studies of human or animal subjects performed by the author. It is a commissioned, peer-reviewed article specifically aimed at giving details of asthma endotypes and the use of the NIOX VERO device in clinical practice.

\section{ENDOTYPES: EXHALED NITRIC OXIDE AND HOW IT RELATES TO ASTHMA}

Initial attempts at subdividing asthma types were dependent upon careful delineation of the observable characteristics and clinical features, the phenotype. Originally, this led to a division between intrinsic and extrinsic asthma. In the last decade, there has been a renewed enthusiasm within the research community to split, or subdivide, the asthma phenotype [5]. This renewed interest has, to an extent, been the result of increased availability of mathematical modelling to approach the available patient data [6]. This has resulted in a 're-discovery' of work initially conducted in Derby in the late 1950s that identified the importance of sputum eosinophilia in determining treatment response [7, 8].

Phenotypical analysis is fraught with difficulty. Most biological characteristics or laboratory indices are not dichotomous but continuous; moreover, they are variable over time and influenced by treatment. In an attempt to resolve these difficulties, there has been a shift away from phenotyping to endotyping [9]. An endotype is defined by a distinct functional or pathobiological mechanism. This has led to the identification of new distinct groups of children and adults with asthma. Some examples of how phenotypes may overlap with multiple endotypes in children and adults are given in Table 2.

The relationship between exhaled nitric oxide (eNO) and asthma is complex. Nitric oxide is produced by nitric oxide synthase (NOS) enzymes and is extremely short lived unlike other biological markers. There are three distinct forms of NOS enzymes: endothelial (eNOS), inducible (iNOS) and neuronal (nNOS). eNO is produced in the lung epithelia as a result of expression of iNOS $[10,11]$. The activity of iNOS is highly variable, and the concentration of eNO on the breath is dependent upon many factors including the degree of type-2 airway 
Table 2 Asthma endotypes and their proposed relationship to phenotypes

\begin{tabular}{|c|c|}
\hline Phenotype & Possible endotypes \\
\hline \multicolumn{2}{|l|}{ Children } \\
\hline Eosinophilic asthma & Allergic asthma, e.g., atopic child with inhaled steroid responsive disease \\
\hline $\begin{array}{l}\text { Exacerbation-prone } \\
\text { asthma }\end{array}$ & Preschool episodic viral induced wheezer, multiple trigger wheezer \\
\hline Exercise-induced asthma & Preschool multiple trigger wheezer (exercise-triggered) \\
\hline $\begin{array}{l}\text { Poorly steroid-responsive } \\
\text { asthma }\end{array}$ & Obesity associated asthma; neutrophilic asthma; steroid-insensitive eosinophilic asthma \\
\hline \multicolumn{2}{|l|}{ Adults } \\
\hline Eosinophilic asthma & $\begin{array}{l}\text { Allergic asthma; aspirin-sensitive asthma; severe late-onset hypereosinophilic asthma; allergic } \\
\text { bronchopulmonary aspergillosis (ABPA) }\end{array}$ \\
\hline $\begin{array}{l}\text { Exacerbation-prone } \\
\text { asthma }\end{array}$ & $\begin{array}{l}\text { Allergic asthma; aspirin-sensitive asthma; late-onset hypereosinophilic asthma; ABPA, } \\
\text { catamenial asthma }\end{array}$ \\
\hline Exercise-induced asthma & Cross-country skiers' asthma, elite-athlete asthma \\
\hline $\begin{array}{l}\text { Poorly steroid-responsive } \\
\text { asthma }\end{array}$ & $\begin{array}{l}\text { Chronic obstructive pulmonary disease overlap; obesity associated asthma; neutrophilic } \\
\text { asthma; steroid-insensitive eosinophilic asthma }\end{array}$ \\
\hline
\end{tabular}

inflammation, presence of other atopic diseases, exposure to environmental tobacco smoke and body mass index (Table 3) [12-20].

Despite this apparent heterogeneity, eNO has established itself within clinical guidelines as a useful adjunct in the diagnosis of asthma in children and adults [21]. Moreover, changes over time within an individual can be extremely helpful in determining response to treatment profiles and indirectly confirming adherence patterns [22].

While eNO concentrations provide evidence of type-2 airway inflammation, FeNO measurement is relatively cheap to perform, is noninvasive and is performed easily in children above 4 years of age. A number of commercially available systems measuring FeNO are available to clinicians, and I have previously written about my experience with one of these (NIOX $\left.\mathrm{MINO}^{\circledR}\right)$ [22].

\section{NIOX VERO ${ }^{\circledR}:$ THE LATEST GENERATION DEVICE TO MEASURE FENO}

There are many devices available commercially for the measurement of FeNO in clinical practice. NIOX VERO $^{\circledR} \quad$ (Fig. 1a) is a point-of-care, hand-held, electrochemical FeNO analyzer and is the next-generation device from the predicate, NIOX $\mathrm{MINO}^{\circledR}$ (Fig. 1b). NIOX VERO $^{\circledR}$ complies with all essential aspects of the American Thoracic Society (ATS) and European Respiratory Society (ERS) recommendations for standardized exhaled NO measurement procedures [23] and has been recently cleared for use in the US, Japan and China. In order to complete this review article, I contacted the manufacturer of the NIOX VERO ${ }^{\circledR}$ device to determine what validation had been undertaken prior to its release. These data were provided upon request 
Table 3 Factors known to be associated with fractional exhaled nitric oxide concentrations in children and adults with asthma

\begin{tabular}{ll}
\hline Increased FeNO & Decreased FeNO \\
\hline Airway eosinophilia [13] & $\begin{array}{c}\text { Environmental tobacco } \\
\text { smoke exposure [14] } \\
\text { Total IgE [15-17] }\end{array}$ \\
$\begin{array}{c}\text { Neonatal respiratory } \\
\text { distress syndrome [16] }\end{array}$ \\
$\begin{array}{c}\text { Ingestion of nitrate rich } \\
\text { foods, e.g., lettuce [18] }\end{array}$ \\
$\begin{array}{c}\text { Increased environmental } \\
\text { pollution [19] }\end{array}$ & Female gender [20] \\
\hline
\end{tabular}

$\mathrm{FeNO}$ fractional exhaled nitric oxide, IgE immunoglobulin E

A

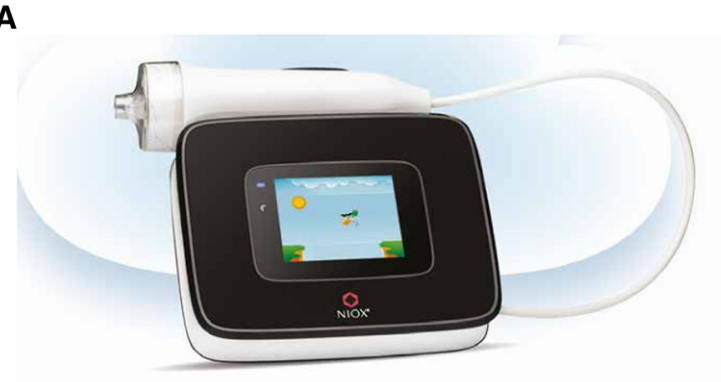

B

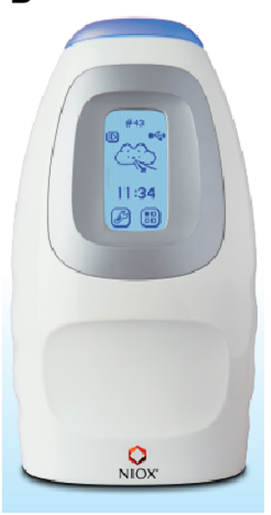

Fig. 1 a The NIOX VERO ${ }^{\circledR}$ portable exhaled nitric oxide analyzer. b The NIOX MINO ${ }^{\circledR}$ portable exhaled nitric oxide analyzer

by Cirassia/Aerocrine. To date, two technical validation studies and two clinical validation studies have been performed by the manufacturer that have supported the clinical utility of NIOX VERO ${ }^{\circledR}$, the results of which are summarized in the following sections.

\section{DATA SUPPORTING PRECISION AND ACCURACY}

To calculate the precision and accuracy, mixtures of a certified calibration gas of $200 \mathrm{ppb}$ NO in nitrogen were used, yielding concentrations of 5, 25, 75 and $200 \mathrm{ppb}$. The gas mixer was connected in line with the NIOX $\mathrm{VERO}^{\circledR}$ instrument, and five sensors were mounted in five NIOX VERO ${ }^{\circledR}$ instruments.

\section{Precision}

This was determined in house by the manufacturer. Two replicate determinations of each concentration were made twice a day (more than $2 \mathrm{~h}$ apart) for 20 days. The repeatability and within-device precision were calculated for five instruments. Both standard deviation (SD) estimates met the precision claim at all four concentration levels, and the repeatability and within-device precision were well within the specification limit: $<3 \mathrm{ppb}$ of measured values $<30 \mathrm{ppb}$ and $<10 \%$ of measured values $>30 \mathrm{ppb}$. Both $\mathrm{SD}$ estimates for repeatability and within-device precision met the precision claim in the labeling at all four concentration levels.

\section{Accuracy}

This is the deviation of the measured value from a known nominal value, i.e., the certified concentration of a NO reference standard. Two replicate determinations were made at each occasion. For each test occasion the mean NO concentration $(M)$ for each set of replicates and 
the absolute deviation of each replicate mean

$(D)$ from the nominal gas concentration $(G)$ were calculated. The mean $D$, SD and $95 \%$ confidence interval (CI) for all instruments were calculated. At $>50 \mathrm{ppb}$ concentration levels, $D$ is expressed as a percentage of the nominal NO concentration. The results for the five NIOX $\mathrm{VERO}^{\circledR}$ systems showed the accuracy was within the technical specification: $\pm 5 \mathrm{ppb}<50 \mathrm{ppb}$ or maximum $10 \%$ at $>50 \mathrm{ppb}$.

\section{DATA-SUPPORTING AGREEMENT AND REPEATABILITY}

\section{NIOX VERO ${ }^{\circledast}$ Versus NIOX MINO ${ }^{\circledR}$ : Are the Results Obtained Comparable in Clinical Practice?}

Pooled data from two randomized, multi-center, single-visit studies in 112 subjects aged $\geq 7$ years demonstrated clinically acceptable agreement between the NIOX VERO $^{\circledR}$ and NIOX MINO $^{\circledR}$ devices and supported a high degree of intra-subject repeatability with the new device. The mean observed paired difference for the first valid FeNO measurement on each device was $-4.6 \mathrm{ppb} \quad(95 \%) \quad \mathrm{CI}-5.825$ to -3.377 ; $p<0.0001)$. Weighted Deming regression analysis showed paired differences were centered close to 0. Agreement was also seen when comparing the first valid FeNO measurement or the mean of two measurements. Intra-subject repeatability of NIOX $\mathrm{VERO}^{\circledR}$ was significantly better than for NIOX $\mathrm{MINO}^{\circledR}(p=0.0112)$. Although FeNO measurements using the NIOX VERO $^{\circledR}$ were slightly lower than with the $\mathrm{NIOX} \mathrm{MINO}^{\circledR}$, there were no substantial differences between replicates within age groups, gender groups or randomization sequences, and the difference was within the technical specifications of the device (Fig. 2).

\section{Inter-Operator Repeatability}

Pooled data from two multi-center, single-visit, point-of-care studies showed that NIOX VERO ${ }^{\circledR}$

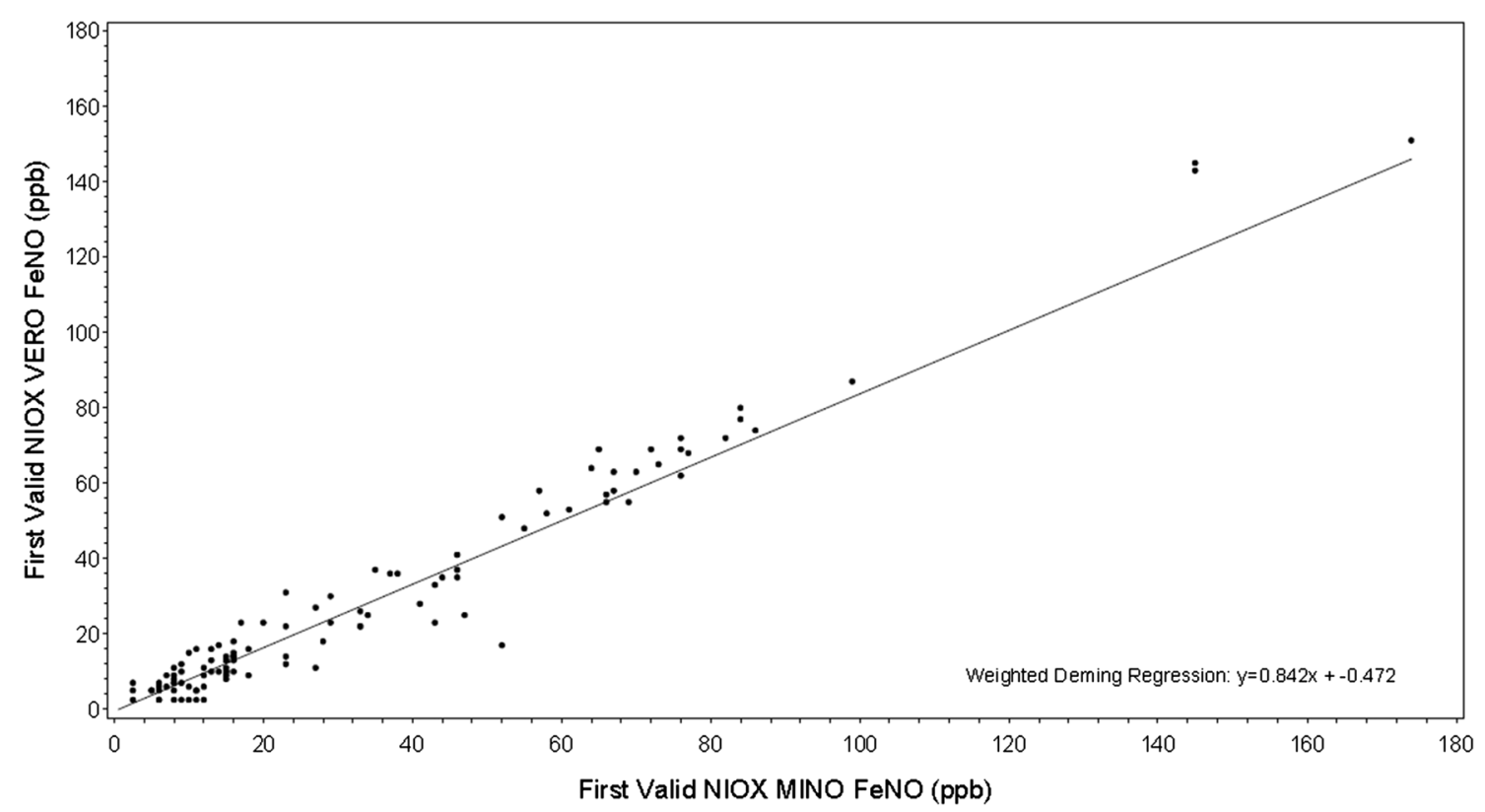

Fig. 2 Agreement and repeatability data for NIOX VERO ${ }^{\circledR}$ 
gave repeatable and consistent FeNO measurements with no observable pattern of training effect or order effect on FeNO when measured three times by three different operators. The studies were performed in 122 subjects aged $\geq 7$ years with physician-diagnosed asthma; the majority had mean FeNO values of $<50 \mathrm{ppb}$ with a mean of $31.4 \pm 32.97 \mathrm{ppb}$ overall and ranged from 5 to $174 \mathrm{ppb}$. Intra-subject mean FeNO values were not significantly different for subjects with FeNO $<50 \mathrm{ppb}$ versus those with $\geq 50 \mathrm{ppb}$ $(p=0.9979$ versus $p=0.8006)$. A total of 54 operators participated, of which $46 \%$ were registered nurses and $20 \%$ were licensed practical nurses or had an associated nursing degree. Inter-operator repeatability was demonstrated with a mean intra-subject variance of $6.61 \pm 17.954 \mathrm{ppb}$ (upper $95 \% \mathrm{CI}$ 9.41). The coefficient of variance was $0.066 \pm 0.054$ (upper $95 \%$ CI 0.074) (Fig. 3).

Weighted Deming regression analysis of the three possible pairs of measurements showed no evidence of bias relating to the order of testing with an estimated bias of $<2 \%$ for all pairs; these findings provided further evidence of repeatability. Repeatability was also shown for those subjects with a mean FeNO $<50 \mathrm{ppb}$, the within-subject paired FeNO difference was $<10 \mathrm{ppb}$, and the majority of subjects (97\%) with a mean FeNO $\geq 50$ ppb had a difference $\leq 20 \%$. Hence, while the variability in intra-subject FeNO values increased with higher values, the CVs (upper $95 \% \mathrm{CI}$ ) from both subject groups remained similar [0.072 (0.082) versus $0.048(0.060)]$.

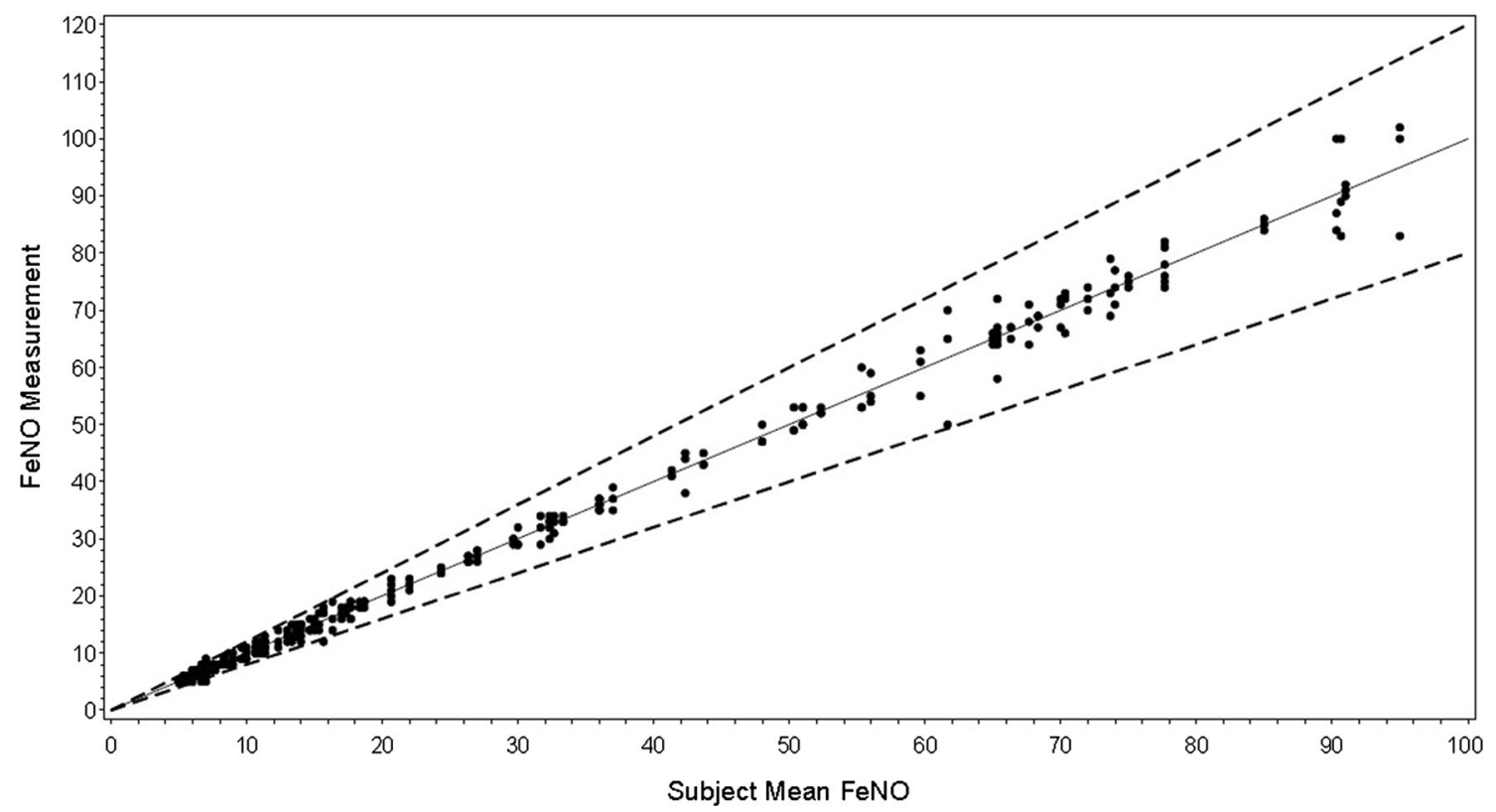

Fig. 3 Individual fractional exhaled nitric oxide measurements versus subject mean fractional exhaled nitric oxide measurements for pooled study data efficacy subjects Note: Subjects with a FeNO measurement recorded as $<5 \mathrm{ppb}$ were considered to have a FeNO measurement $=5 \mathrm{ppb}$. Note: Dashed lines represent lines of slope $=1.2$ and 0.8 . fenores.fig generated by fenores.sas on 11AUG14: 11:36 


\section{Ease of Use}

The NIOX VERO ${ }^{\circledR}$ device provides a slightly different user experience with some advantages over the NIOX $\mathrm{MINO}^{\circledR}$ device. My personal observation in clinical practice with children and adolescents is that the 'in-built' nature of the incentive software is advantageous and reduces the overall 'set-up' time required to obtain a single measurement. In most other respects, the user experience and feedback are equivalent, and even young children (4 years and older) are able to perform measurements using the 6-s mode (see below) after relatively little coaching.

A user-device interaction two-center study was conducted in eight female users who reported Swedish as their primary language and held education in healthcare; none had previous experience with the NIOX VERO ${ }^{\circledR}$ device, but seven of eight were familiar with NIOX MINO ${ }^{\circledR}$. All users could operate the device and assess user-device instructions with the NIOX Panel. The majority of tasks were completed without assistance (75\%); one user required help to create a quality control (QC) user and perform a QC test, and two users needed assistance to handle the exemption at foreseeable misuses and stop exhaling before the analysis time was finished; the observer indicated that only one user actually needed help. Where one was worst imaginable and five were best imaginable, the overall impression was rated between 3 and 4, while ease-of-use and visual impression were rated between 4 and 5 .

\section{Are There Improvements over NIOX $\mathrm{MINO}^{\circledR}$ ?}

As already shown, intra-subject repeatability of the NIOX VERO ${ }^{\circledR}$ is significantly better than for NIOX MINO ${ }^{\circledR}$. Moreover, NIOX VERO ${ }^{\circledR}$ can be used without connection to a power supply and better visibility of the display screen, enabling a degree of portability and flexibility in the clinical setting. Experienced users of the NIOX $\mathrm{MINO}^{\circledR}$ will undoubtedly recall the frustration of an accidental power cable disconnection (usually by the child) after a successful exhalation prior to the calculation of the eNO value. As with NIOX MINO ${ }^{\circledR}$, the NIOX VERO ${ }^{\circledR}$ can be operated using the 10- and 6-5 exhalation modes in a clinical setting and in young children aged 4 years and older. The 6-s mode is particularly useful in clinical practice with younger children.

A randomized, single-visit, clinical validation study was conducted using NIOX $\mathrm{VERO}^{\circledR}$ in asthmatic children aged 4-10 years. Data from the subgroup aged 6-10 years (mean age 8.1 years) showed a high level of agreement between the 6- and 10-s modes, and this was further demonstrated using a Weighted Deming regression analysis in which the intercept was 0 and slope was 1.0. Furthermore, FeNO measurements were repeatable with a median intra-subject SD of 0.707 for both modes and no significant differences $(p=0.3090)$. Children in the subgroup aged 4-5 years also successfully used the NIOX VERO ${ }^{\circledR}$ using the 6- and 10-s modes, with greater success seen using the former. Mean FeNO results were comparable between the 6-s (12.6 ppb) and 10-s (10.6 ppb) modes (Table 4).

\section{DATA TO SUPPORT MEASURING FENO IN CLINICAL PRACTICE}

FeNO provides a complementary and noninvasive assessment of airway inflammation when used alongside more traditional methods, such as history, examination, spirometry and bronchial lability 
Table 4 Fractional exhaled nitric oxide results for subjects aged $4-5$ years by exhalation time mode

\begin{tabular}{ll}
\hline Number of subjects & $\mathbf{1 2}$ \\
\hline FeNO 6 s-mode (ppb) & \\
$\begin{array}{l}\text { Number who successfully completed at } \\
\text { least one measurement (\%) }\end{array}$ & $10(83.3)$ \\
Mean FeNO (standard deviation) & $12.6(13.28)$ \\
Median & 9.0 \\
Minimum, maximum & 5,49 \\
FeNO 10 s-mode (ppb) & \\
Number who successfully completed at & $7(58.3)$ \\
least one measurement (\%) & \\
Mean FeNO (SD) & $10.6(4.86)$ \\
Median & 10.0 \\
Minimum, maximum & 5,19 \\
\hline
\end{tabular}

$\mathrm{FeNO}$ fractional exhaled nitric oxide

measures [24-26]. It provides a more complete assessment of asthma severity and control $[27,28]$ than traditional assessments, has utility in primary care settings and can be measured in patients of most ages. Furthermore, FeNO is useful for monitoring adherence to anti-inflammatory medications and predicting exacerbation risk [27, 29] and offers potential cost savings [26, 30, 31].

\section{Diagnosis}

In primary care clinical practice, the monitoring of asthma control is currently focused on evaluating clinical symptoms and lung function parameters. However, GINA guidelines and ATS FeNO guidelines suggest that airway inflammation could be assessed to optimize treatment strategies [11, 32, 33].

FeNO is used to define and confirm airway allergic and eosinophilic inflammation in patients with asthma [16]. Routine use of
FeNO alongside traditional clinical assessments may improve diagnostic accuracy and enables tailored therapeutic regimens $[16,34,35]$. In a study comparing FeNO and sputum cell counts with serial spirometry and peak flow recordings in children and adults, the sensitivity of spirometry was lower $(47 \%)$ than that of either FeNO (88 \%) or sputum induction $(86 \%)[32,36]$. In addition, FeNO and sputum eosinophils showed a specificity of $92 \%$ compared with $73 \%$ for spirometry $[32,36]$.

Given that $\mathrm{FeNO}$ is representative of Th2-driven local inflammation specifically in the bronchial mucosa [32, 37-39], it has the potential to predict the response to ICS therapy in asthma [3, 40-46]. Data suggest that asthma patients who have elevated baseline FeNO levels are more likely to respond to ICS than those with baseline FeNO levels within predefined normal ranges [32, 40, 41, 47]. However, there is conflicting evidence: in a study by Klaassen et al., symptoms not FeNO levels predicted response to ICS [48], and Prieto et al. showed that FeNO was not useful in predicting response above a baseline cut-off of 20 ppb [49]. However, in the first study, FeNO was measured using an offline tidal breathing method rather than the recommended online measurement [48].

FeNO is of particular interest for diagnosing and phenotyping asthma in children with suspected asthma, therefore enabling optimal treatment and control (Fig. 4; Table 5). Diagnosing asthma in children, particularly pre-schoolers, can be challenging. The advantage of FeNO is that, unlike other assessments, it does not involve a forced vital capacity maneuver, which makes it easier for children, and especially young children, to perform, therefore aiding cooperation [50]. Furthermore, the measurements are easy, quick to perform in the clinic and 


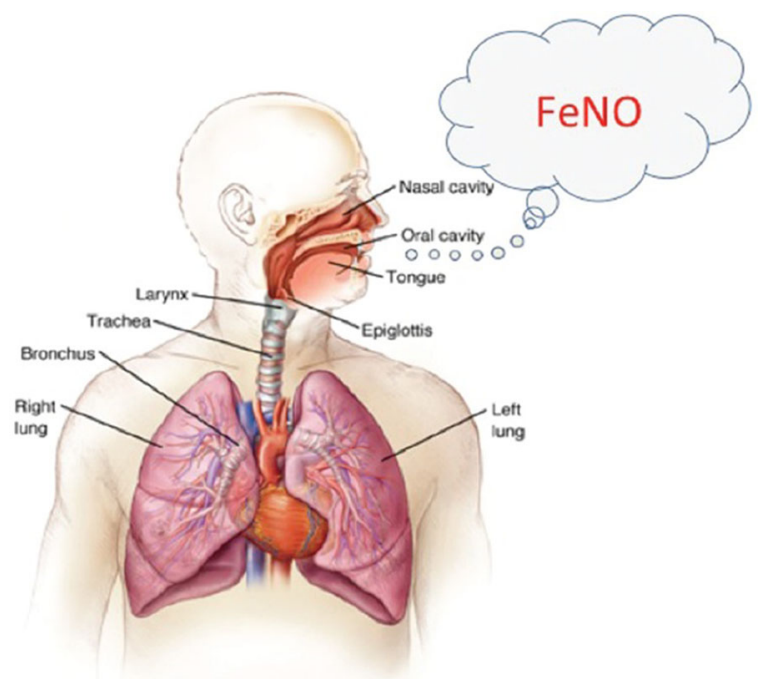

Fig. 4 Fractional exhaled nitric oxide levels can help differentiate between asthma phenotypes (Illustration used with kind permission from Ricciardolo et al. [16])

Table 5 FeNO levels seen in different asthma phenotypes (adapted from [16])

\begin{tabular}{ll}
$\begin{array}{l}\text { Tendency for higher } \\
(>\mathbf{2 6} \mathbf{~ p p b}) \text { FeNO }\end{array}$ & $\begin{array}{l}\text { Tendency for lower } \\
(<\mathbf{1 5} \mathbf{p p b}) \text { FeNO }\end{array}$ \\
\hline $\begin{array}{l}\text { Allergic asthma } \\
\text { Eosinophilic refractory } \\
\text { asthma }\end{array}$ & $\begin{array}{l}\text { Non-atopic asthma } \\
\text { Smoking asthma }\end{array}$ \\
$\begin{array}{l}\text { Non-atopic severe asthma } \\
\text { Poorly controlled/ }\end{array}$ & Obese asthma \\
$\begin{array}{l}\text { exacerbated asthma } \\
\text { ASA-intolerant asthma }\end{array}$ & $\begin{array}{c}\text { Neutrophilic severe asthma } \\
\end{array}$ \\
$\begin{array}{l}\text { Children developing asthma respiratory } \\
\text { (steroid-naive) }\end{array}$ & $\begin{array}{c}\text { Co-existent ciliary } \\
\text { disorders with asthma }\end{array}$ \\
\hline
\end{tabular}

reproducible [51-53], providing cost-effective and real-time inflammatory data $[54,55]$.

\section{Management to Reduce Exacerbations}

Perhaps the most important aspect of incorporating FeNO in asthma management is the reduction in the risk of exacerbations. It is speculated that exacerbations are preceded by an increase in eosinophilic airway inflammation, so FeNO levels may identify patients at risk of exacerbations given the level of cross-correlation between FeNO and symptoms [56, 57].

In clinically stable adults with asthma, the combined use of FeNO and forced expiratory volume in $1 \mathrm{~s}\left(\mathrm{FEV}_{1}\right)$ positively predicted the risk of exacerbation (FeNO $\geq 28 \mathrm{ppb} ; \mathrm{FEV}_{1} \leq 76$ $\%)$ showing an $85 \%$ probability of a future exacerbation, while those with FeNO levels $<28 \mathrm{ppb}$ and $\mathrm{FEV}_{1}>76 \%$ showed no risk of exacerbation $[32,58]$. FeNO may predict loss of control following ICS withdrawal [32, 59, 60], and FeNO has been associated with a positive predictive value of $80-90 \%$ for predicting and diagnosing loss of control [32, 59]. When FeNO was used to guide treatment and manage asthma in pregnant women, there was a substantial reduction in exacerbations in the FeNO-managed group compared to the control group [61].

More recently, three studies have shown that the use of a handheld NO analyzer can reduce exacerbations by as much as $50 \%$ [62-64]. In adults, Syk et al. showed that the use of FeNO to guide treatment alongside usual clinical care reduced the frequency that asthma symptoms worsened [62]. Keeping inflammation under control can reduce the risk of catching a viral infection or having that viral infection lead to an exacerbation. Using FeNO to guide treatment does not lead to fewer symptom-free days but does decrease the frequency of asthma exacerbations [63]. In the study by Peirsman et al., $24 \%$ of children with asthma who were monitored by FeNO experienced exacerbations compared to $48 \%$ from the control group [57], and Petsky et al. reported a smaller percentage of children (22\%) experienced exacerbations when FeNO was utilized to manage their 
asthma, compared to $54 \%$ when it was not [64]. Petsky et al. also showed that taking atopy into account reduces the number of severe exacerbations, although higher doses of ICS were administered. However, they concluded that FeNO is unlikely to be beneficial for improving asthma symptoms. This seems to suggest that symptoms and exacerbations are not related to the same physiological mechanisms, with one more strongly related to airway inflammation and one more strongly related to bronchoconstriction [64].

High FeNO levels in ICS-treated patients usually suggest uncontrolled asthma with high FeNO being correlated with high use of short-acting beta-agonists and oral corticosteroids as well as lower predicted $\mathrm{FEV}_{1}$ levels during the preceding year compared to patients with low FeNO values [65]. In the follow-up study, high FeNO was shown to predict future uncontrolled asthma in patients treated with ICS; by adding FeNO to an asthma control questionnaire and spirometry during routine visits, patients likely to suffer exacerbations could be identified [66].

Negative studies on the use of FeNO for asthma management have been reported $[32,67-70]$. Use of FeNO was not recommended to tailor ICS treatment when compared to managing treatment based on clinical symptoms alone in a meta-analysis in 2009 [70]. However, this meta-analysis did not include many of the most recent studies that demonstrated a decrease in exacerbations, these studies were small, the majority of subjects had mild-to-moderate asthma, and the means of measuring outcomes varied. Indeed, a newer meta-analysis of these data with the addition of newer studies showed the rate of exacerbations to be significantly lower in FeNO-guided children compared with the control group [27]. This result was confirmed recently in a further meta-analysis in children [71]. Combining the results of six eligible studies involving children, the odds ratio of exacerbation was significantly lower in the FeNO-guided management group (OR 0.690, $95 \%$ CI 0.532, 0.895; $p=0.005)$. Further research is planned, and a large multicenter study in the UK is due to start recruitment by the end of 2016.

\section{Adherence and Objective Goals with Patients}

In clinical practice, I have found that FeNO is a very useful indicator of adherence. In particular, unexplained changes in FeNO measurements within an individual over time should prompt a more complete review of medication use. FeNO has the potential to monitor ICS adherence because FeNO responds quickly and dose dependently to ICS treatment [26, 29, 32, 72]-persistently high FeNO levels may indicate poor compliance [73].

Optimum ICS dosing is important for ensuring patient safety while maintaining adequate asthma control [32]. However, in order to obtain these benefits, ICS must be taken regularly, and many studies have shown that treatment compliance among patients with asthma is frequently poor, which leads to loss of control and increased morbidity [74]. Reliably identifying non-compliance could be valuable in improving the understanding of factors contributing to on-going symptoms in asthma [29, 74].

Increased FeNO levels ( $>25 \mathrm{ppb}$ ) in children prescribed ICS was associated with reduced treatment adherence (OR 0.25, $95 \%$ CI 0.15-0.41) [32, 75], and improved ICS adherence correlated with a greater reduction in FeNO in patients with difficult-to-treat asthma [29, 32]. Another study found serial 
FeNO measurements helped to determine treatment adherence and showed that adherence with ICS was significantly associated $(p<0.001)$ with a fall in FeNO over the study period $[12,22]$. Although elevated FeNO levels may reflect poorer adherence, confounding factors such as disease activity and inhaler technique need to be carefully considered [74]. It is not unusual, in my clinical experience, to see an increase in FeNO accompanied by a 'loss of optimal inhaler technique' in many children and young adults. This is often a complete surprise to parents, particularly when they find that the use of large-volume spacers has been abandoned or that other important steps in inhaler use are being omitted.

\section{Cost-Effectiveness and Recent NICE Recommendations}

FeNO is a useful tool for targeting those patients who will benefit from anti-inflammatory treatment [76]. In difficult, poorly controlled asthma, when symptoms may have multiple causes, FeNO may be used to monitor treatment to avoid unnecessary increases in steroid therapy $[76,77]$. This is particularly important in light of financial constraints in healthcare especially given the large cost implication of ineffective treatments. FeNO measurements offer the potential to reduce costs while simultaneously improving the quality of patient care with more accurate phenotypic assessment and precision treatment [76].

In the US, $30 \%$ of asthma patients have severe or difficult-to-treat asthma, achieve suboptimal control and show relative non-responsiveness to medication. It is estimated that this relatively small proportion of patients accounts for $80 \%$ of asthma medical costs [31]. Adding FeNO to standard asthma management offers potential cost savings. The inclusion of FeNO measurements may ensure parity was reached with the current standard of care in the US, assuming a reduction of $5 \%$ in hospitalization and emergency department costs; this is despite the costs of performing the FeNO tests [31].

The cost effectiveness of FeNO was investigated in a German study [30]. Based on a reimbursement price of $€ 34$ using the portable analyzer, NIOX $\mathrm{MINO}^{\circledR}$, an asthma diagnosis cost $€ 12$ more per patient than standard diagnostic methods, but offered improved accuracy. The use of FeNO in treatment decisions was less costly than standard asthma management and provided similar health benefits.

In the UK, FeNO is recommended by the National Institute for Health and Care Excellence (NICE) as a cost effective measurement for the diagnosis and management of asthma when used as an adjunct to traditional clinical testing [26]. NICE also considers FeNO as a potential tool for monitoring treatment adherence [26]. NICE compared the use of three NO analyzers (NIOX MINO $^{\circledR}$, NIOX VERO ${ }^{\circledR}$ and NOBreath) with current standard tests used in England and Wales [26]. Base-case results for asthma management in children and adults indicated that the use of FeNO alongside tests recommended by the British guidelines produced a small health benefit in terms of disease burden [0.05 quality-adjusted life year (QALY)] when compared to following the British guidelines alone (0.04 QALY), although the addition of FeNO increased costs because of projected ICS use. Their review also showed that FeNO testing plus bronchodilator reversibility testing in adults and children delivered equal or greater QALYs at a lower incremental cost-effectiveness ratio (ICER) than other tests 
and that FeNO assessment in conjunction with existing tests was more cost-effective than when existing tests were used alone. They concluded that FeNO was both cost and clinically effective when used to support symptomatic asthma management in adults and children using ICS, with the caveat that the results should be interpreted with caution given the uncertainty relating to the economic models used. FeNO is not recommended to help the stepping down of ICS use [26].

\section{FUTURE RESEARCH}

In the UK, measurement of FeNO has gradually crept into clinical practice. Initial concerns about cost and the reliability of the measurements have been replaced largely with a growing enthusiasm as clinicians have found the technology easy to use and helpful in guiding treatment decisions. This change was reflected in the recent interim NICE guidance on diagnosis and management of asthma [26]. Nonetheless, many uncertainties exist, and there are still large gaps in the evidence base, particularly in children.

\section{Pre-School Wheeze and FeNO}

As I reflect upon clinical practice in wheezing pre-school children, I am reminded of the aphorism popularized by Maslow: 'If all you have is a hammer then everything looks like a nail' [78]. Thus, for clinicians there is a temptation to label everything that wheezes as asthma as treatments are both available and of proven efficacy. Pre-school wheeze is a common problem, affecting up to a third of all children $[79,80]$. The disappointing results from recent randomized controlled studies in this group of children have highlighted the lack of evidence for any effective treatments in an unrefined population of early-onset wheezers [81, 82]. There is an urgent need for improved identification of endotypes in young wheezy children, particularly those who present acutely and recurrently to hospital with viral-induced wheeze.

Current treatment strategies broadly separate children into two distinct groups: those with episodic viral symptoms or those with multiple triggers $[79,80]$. In clinical practice, intuition and experience are required as parental report alone is often misleading [83]. Despite a paucity of evidence, children with recurrent symptoms are often treated speculatively with either increasing doses of ICS or LTRA. FeNO discriminates between different subtypes of wheeze and predicts the likely natural history $[84,85]$. Studies are now required to determine whether FeNO plus clinical parameters can be used to predict response (or non-response) to any treatment.

\section{Longitudinal Measurement of FeNO and Home Measurement}

Studies in which longitudinal measures of FeNO have been used to drive clinical decisions have not been wholly successful in either adults or children [32]. This is probably due to a number of factors including differences in study design, sample size, methodology, the application of different FeNO algorithms and devices, and inconsistencies in predefined study endpoints. The desire to define a single value upon which treatment decisions are based is almost certainly a big limitation and works contrary to everything that is known about personalized medicine.

The (lack of) evidence here seems at odds with what is known about the biology and clinical experience. In clinical practice, a 
change in FeNO (in either direction) in an individual patient can give important clues about adherence (intentional or non-intentional) and even predict a likely moderate exacerbation in advance of other symptoms [57]. Daily measurement of FeNO is not practical for most clinical care and would only be possible if home monitoring was available. Home use of spirometry to enhance clinical management in children has been disappointing, largely because effort diminishes in most individuals over time $[86,87]$. However, FeNO measurement is less effort dependent and may allow rational treatment adjustments to be made between clinic appointments in response to variation in airway inflammation.

\section{CONCLUSION}

Throughout the last decade we have appeared to be on the threshold of an era of personalized medicine for asthma. Despite the regular headlines and breakthrough discoveries, this has mostly failed to emerge and make its way into clinical practice. However, a change of approach moving away from classic phenotyping and the identification of biologically relevant endotypes is already bearing fruit. The measurement of $\mathrm{FeNO}$ is helpful in securing an accurate diagnosis, and data are emerging showing that FeNO-guided management is likely to reduce the risk of exacerbation. The NIOX VERO ${ }^{\circledR}$ device builds upon existing sensor technologies to provide accurate, easy, point-of-care measurement of FeNO. Its clear, user-friendly display and portability represent significant improvements over preceding devices while matching their accuracy and precision.

\section{ACKNOWLEDGMENTS}

Kathryn White of Cathean Ltd. medical writing services provided written and editorial support for this manuscript; the funding for this was provided by Circassia/Aerocrine. Technical data on the NIOX VERO $^{\circledR}$ device were provided by Circassia/Aerocrine on request, and the manufacturer of the agent under review was also offered an opportunity to comment on the article. Changes resulting from comments received were made by the author based on their scientific and editorial merit. No funding or sponsorship was received for this study or publication of this article. The author meets the International Committee of Medical Journal Editors (ICMJE) criteria for authorship for this manuscript and takes responsibility for the work as a whole and has given final approval for the version to be published.

Disclosures. In the last 5 years, WD Carroll has received honoraria and speaker fees from Aerocrine, Alk-Abello, GlaxoSmithKline and Novartis. He is Editor-in-Chief of a journal (Paediatrics and Child Health) that is cited in this review.

Compliance with Ethics Guidelines. This article is based on previously conducted studies and does not involve any new studies of human or animal subjects performed by the author.

Open Access. This article is distributed under the terms of the Creative Commons Attribution-NonCommercial 4.0 International License (http://creativecommons.org/licenses/ by-nc/4.0/), which permits any 
noncommercial use, distribution, and reproduction in any medium, provided you give appropriate credit to the original author(s) and the source, provide a link to the Creative Commons license, and indicate if changes were made.

\section{REFERENCES}

1. Lemanske RF, Mauger DT, Sorkness CA, et al. Step-up therapy for children with uncontrolled asthma receiving inhaled corticosteroids. NEJM. 2010;362:975-85.

2. Rogers AJ, Tantisira KG, Fuhlbrigge AL, For the Childhood Asthma Management Program (CAMP), et al. Predictors of poor response during asthma therapy differ with definition of clinical outcome. Pharmacogenomics. 2009;10:1231-42.

3. Szefler SJ, Phillips BR, Martinez FD, et al. Characterization of within-subject responses to fluticasone and montelukast in childhood asthma. J Allergy Clin Immunol. 2005;115:233-42.

4. Tantisira KG, Fuhlbrigge AL, Tonascia J, et al. Bronchodilation and bronchoconstriction: predictors of future lung function in childhood asthma. J Allergy Clin Immunol. 2006;117:1264-71.

5. Gauthier M, Ray A, Wenzel SE. Evolving concepts of asthma. Am J Respir Crit Care Med. 2015;192:660-8.

6. Moore WC, Meyers DA, Wenzel SE, National Heart, Lung, and Blood Institute's Severe Asthma Research Program, et al. Identification of asthma phenotypes using cluster analysis in the Severe Asthma Research Program. Am J Respir Crit Care Med. 2010;181:315-23.

7. Brown HM. Treatment of chronic asthma with prednisolone; significance of eosinophils in the sputum. Lancet. 1958;2:1245-7.

8. Brown HM. Asthma, allergy and steroids. Br J Clin Pract. 1961;15:1001-17.

9. Anderson GP. Endotyping asthma: new insights into key pathogenic mechanisms in a complex, heterogeneous disease. Lancet. 2008;372:1107-19.

10. Van Den Toorn LM, Overbeek SE, De Jongste JC, Leman K, Hoogsteden HC, Prins J-B. Airway inflammation is present during clinical remission of atopic asthma. Am J Respir Crit Care Med. 2001;164:2107-13.
11. Dweik RA, Boggs PB, Erzurum SC, On behalf of the American Thoracic Society Committee on Interpretation of Exhaled Nitric Oxide Levels (FeNO) for Clinical Applications, et al. An official ATS clinical practice guideline: interpretation of exhaled nitric oxide levels (FeNO) for clinical applications. Am J Respir Crit Care Med. 2011;184:602-15.

12. Beck-Ripp J, Griese M, Arenz S, Koring C, Pasqualoni B, Bufler P. Changes of exhaled nitric oxide during steroid treatment of childhood asthma. Eur Respir J. 2002;19:1015-9.

13. Warke TJ, Fitch PS, Brown V, et al. Exhaled nitric oxide correlates with airway eosinophils in childhood asthma. Thorax. 2002;57:383-7.

14. Laoudi Y, Nikasinovic L, Sahraoui F, Grimfeld A, Momas I, Just J. Passive smoking is a major determinant of exhaled nitric oxide levels in allergic asthmatic children. Allergy. 2010;65:491-7.

15. Pijnenburg MW, De Jongste JC. Exhaled nitric oxide in childhood asthma: a review. Clin Exp Allergy. 2008;38:246-59.

16. Ricciardolo FLM, Silvestri M, Pistorio A, et al. Determinants of exhaled nitric oxide levels (FeNO) in childhood atopic asthma: evidence for neonatal respiratory distress as a factor associated with low FeNO levels. J Asthma 2010;47:810-16. Taylor \& Francis Ltd. http://www.informaworld. com).

17. Janson C, Kalm-Stephens P, Foucard T, Norback D, Alving K, Nordvall SL. Exhaled nitric oxide levels in school children in relation to IgE sensitisation and window pane condensation. Respir Med. 2005;99:1015-21.

18. Vints AM, Oostveen E, Eeckhaut G, Smolders M, De Backer WA. Time-dependent effect of nitrate-rich meals on exhaled nitric oxide in healthy subjects. Chest. 2005;128:2465-70.

19. Flamant-Hulin $M$, Caillaud D, Sacco P, Pénard-Morand C, Annesi-Maesano I. Air pollution and increased levels of fractional exhaled nitric oxide in children with no history of airway damage. J Toxicol Environ Health A. $2009 ; 73: 272-83$.

20. Wong GWK, Liu EKH, Leung TF, et al. High levels and gender difference of exhaled nitric oxide in Chinese school children. Clin Exp Allergy. 2005;35:889-93.

21. Interim NICE guidance for diagnosis and management of asthma. https://www.nice.org.uk/ guidance/GID-CGWAVE0640/documents/interimfindings. Accessed March 2016. 
22. Ruggins N, Carroll W. Managing childhood asthma: clinical experience with the measurement of fractional exhaled nitric oxide (FeNO). Paediatr Child Health. 2014;24:260-3.

23. American Thoracic Society; European Respiratory Society. ATS/ERS recommendations for standardized procedures for the online and offline measurement of exhaled lower respiratory nitric oxide and nasal nitric oxide. Am J Respir Crit Care Med. 2005;171:912-30.

24. Turner S. Exhaled nitric oxide and the management of childhood asthma-yet another promising biomarker "has been" or a misunderstood gem. Paediatr Respir Rev. 2014;16:88-96.

25. Brodlie M, McKean MC. Exhaled nitric oxide in the diagnosis of childhood asthma. A small but important piece of the clinical jigsaw. BMJ. 2009;339:b5418.

26. NICE diagnostic adoption support for measuring fractional exhaled nitric oxide concentration in asthma: NIOX MINO, NIOX VERO and NObreath: insights from the NHS. NICE Diagnostic Support [HTDG12]. April 2014. Available as pdf at: https:// www.nice.org.uk/guidance/htdg12/chapter/1-Exe cutive-summary. Accessed March 2016.

27. Mahr TA, Malka J, Spahn JD. Inflammometry in pediatric asthma: a review of fractional exhaled nitric oxide in clinical practice. Allergy Asthma Proc. 2013;34:210-9.

28. Carroll WD. Limitations of asthma control questionnaires in the management and follow up of childhood asthma. Paed Resp Rev. 2013;14(4):229-31.

29. McNicholl DM, Stevenson M, McGarvey LP, Heaney LG. The utility of fractional exhaled nitric oxide suppression in the identification of nonadherence in difficult asthma. Am J Respir Crit Care Med. 2012;186:1102-8.

30. Berg J, Lindgren P. Economic evaluation of $\mathrm{FE}_{\mathrm{NO}}$ measurement in diagnosis and 1-year management of asthma in Germany. Respir Med. 2008;102:219-31.

31. Bukstein D, Luskin AT, Brooks EA. Exhaled nitric oxide as a tool in managing and monitoring difficult-to-treat asthma. Allergy Asthma Proc. 2011;32:185-92.

32. Bjermer L, Alving K, Diamant Z, et al. Current evidence and future research needs for FeNO measurement in respiratory diseases. Respir Med. 2014;108:830-41.

33. Global strategy for asthma management and prevention. 2015. http://www.ginasthma.org. Accessed 15 Apr 2016.
34. La Force C, Brooks E, Herje N, et al. Impact of exhaled nitric oxide measurements on treatment decisions in an asthma specialty clinic. Ann Allergy Asthma Immunol. 2014;113:619-23.

35. Price D, Ryan D, Burden A, et al. Using fractional exhaled nitric oxide (FeNO) to diagnose steroid-responsive disease and guide asthma management in routine care. Clin Transl Allergy. 2013;3:37.

36. Smith AD, Cowan JO, Filsell S, et al. Diagnosing asthma: comparisons between exhaled nitric oxide measurements and conventional tests. Am J Respir Crit Care Med. 2004;169:473-8.

37. Alving K, Malinovschi A. Basic aspects of exhaled nitric oxide. Eur Respir Monogr. 2010;49:1-31.

38. Lemiere C, Ernst P, Olivenstein R, et al. Airway inflammation assessed by invasive and noninvasive means in severe asthma: eosinophilic and non-eosinophilic phenotypes. J Allergy Clin Immunol. 2006;118:1033-9.

39. Haldar P, Brightling CE, Hargadon B, et al. Mepolizumab and exacerbations of refractory eosinophilic asthma. N Engl J Med. 2009;360:973-84.

40. Smith AD, Cowan JO, Brassett KP, et al. Exhaled nitric oxide: a predictor of steroid response. Am J Respir Crit Care Med. 2005;172:453e9.

41. Hahn PY, Morgenthaler TY, Lim KG. Use of exhaled nitric oxide in predicting response to inhaled corticosteroids for chronic cough. Mayo Clin Proc. 2007;82:1350-5.

42. Zietkowski Z, Kucharewicz I, Bodzenta-Lukaszyk A. The influence of inhaled corticosteroids on exhaled nitric oxide in stable chronic obstructive pulmonary disease. Respir Med. 2005;99:816-24.

43. Antus B. Role of exhaled nitric oxide in predicting steroid response in chronic obstructive pulmonary disease. Orv Hetil. 2010;151:2083-8.

44. Calhoun WJ, Ameredes BT, King TS, et al. Comparison of physician-, biomarker-, and symptom-based strategies for adjustment of inhaled corticosteroid therapy in adults with asthma: the BASALT randomized controlled trial. JAMA. 2012;308:987-97.

45. Petsky HL, Cates CJ, Lasserson TJ, et al. A systematic review and meta-analysis: tailoring asthma treatment on eosinophilic markers (exhaled nitric oxide or sputum eosinophils). Thorax. 2012;67:199-208.

46. Donohue JF, Jain N. Exhaled nitric oxide to predict corticosteroid responsiveness and reduce asthma exacerbation rates. Respir Med. 2013;107:943-52. 
47. Silkoff PE, McClean P, Spino M, Erlich L, Slutsky AS, Zamel N. Dose-response relationship and reproducibility of the fall in exhaled nitric oxide after inhaled beclomethasone dipropionate therapy in asthma patients. Chest. 2001;119:1322-8.

48. Klaassen EM, van Kant KD, Jobsis Q, et al. Symptoms, but not a biomarker response to inhaled corticosteroids, predict asthma in preschool children with recurrent wheeze. Mediat Inflamm. 2012;2012:162571.

49. Prieto L, Ferrer A, Ponce S, Palop J, Marin J. Exhaled nitric oxide measurement is not useful for predicting the response to inhaled corticosteroids in subjects with chronic cough. Chest. 2009; 136:816-22.

50. Hanson JR, De Lurgio SA, Williams DD, Dinakar C. Office-based exhaled nitric oxide measurement in children 4 years of age and older. Ann Allergy Asthma Immunol. 2013;11:358-63.

51. Dinakar C. Exhaled nitric oxide in pediatric asthma. Curr Allergy Asthma Rep. 2009;9:30-7.

52. Pijnenburg MW, Merkus PJ. NO kidding: exhaled nitric oxide fraction in preschool children. Eur Repir J. 2015;45:30-2.

53. Ratnawati R, Thomas PS. Exhaled nitric oxide in paediatric asthma. Chron Respir Dis. 2005;2:163-74.

54. Sivan Y, Gadish T, Fireman E, Soferman R. The use of exhaled nitric oxide in the diagnosis of asthma in school children. J Pediatr. 2009;155:211-6.

55. Bush A, Eber E. The value of FeNO measurement in asthma management: the motion for Yes, it's NOor, the wrong end of the stick! Paediatr Respir Rev. 2008;9:127-31.

56. Ferrante G, Malizia V, Antona R, Corsello G, La Grutta $S$. The value of FeNO measurement in childhood asthma: uncertainties and perspectives. Multidiscip Respir Med. 2013;8:50.

57. Van der Valk RJ, Caudri D, Savenije O, et al. Childhood wheezing phenotypes and FeNO in atopic children at age 8. Clin Exp Allergy. 2012;42:1329-36.

58. Gelb AF, Flynn Taylor C, Shinar CM, Gutierrez C, Zamel N. Role of spirometry and exhaled nitric oxide to predict exacerbations in treated asthmatics. Chest. 2006;129:1492-9.

59. Jones SL, Kittelson J, Cowan JO, et al. The predictive value of exhaled nitric oxide measurements in assessing changes in asthma control. Am J Respir Crit Care Med. 2001;164:738-43.
60. Pijnenburg MW, Hofhuis W, Hop WC, De Jongste JC. Exhaled nitric oxide predicts asthma relapse in children with clinical asthma remission. Thorax. 2005;60:215-8.

61. Powell H, Murphy VE, Taylor DR, et al. Management of asthma in pregnancy guided by measurement of fraction of exhaled nitric oxide: a double blind, randomised controlled trial. Lancet. 2011;378:983-90.

62. Syk J, Malinovschi A, Johansson G, et al. Anti-inflammatory treatment of atopic asthma guided by exhaled nitric oxide: a randomized, controlled trial. J Allergy Clin Immunol Pract. 2013;1:639-48.

63. Peirsman EJ, Carvelli TJ, Hage PY. Exhaled nitric oxide in childhood allergic asthma management a randomised controlled trial. Pediatr Pulmonol. 2013;. doi:10.1002/ppul.22873.

64. Petsky HL, Li AM, Kynaston JA, Turner C, Chang AB. Management based on exhaled nitric oxide levels adjusted for atopy reduces asthma exacerbations in children: a dual centre randomized controlled trial. Pediatr Pulmonol. 2015;50:535-43.

65. Zeiger RS, Schatz M, Zhang F, et al. Association of exhaled nitric oxide to asthma burden in asthmatics on inhaled corticosteroids. J Asthma. 2011;48:8-17.

66. Zeiger RS, Schatz M, Zhang F, et al. Elevated exhaled nitric oxide is a clinical indicator of future uncontrolled asthma in asthmatic patients on inhaled corticosteroids. J Allergy Clin Immunol. 2011;128:412-4.

67. Szefler SJ, Mitchell H, Sorkness CA, et al. Management of asthma based on exhaled nitric oxide in addition to guideline-based treatment for inner-city adolescents and young adults: a randomised controlled trial. Lancet. 2008;372:1065-72.

68. de Jongste JC, Carraro S, Hop WC, Baraldi E. Daily telemonitoring of exhaled nitric oxide and symptoms in the treatment of childhood asthma. Am J Respir Crit Care Med. 2009;179:93-7.

69. Shaw DE, Berry MA, Thomas M, et al. The use of exhaled nitric oxide to guide asthma management: a randomized controlled trial. Am J Respir Crit Care Med. 2007;176:231-7.

70. Petsky HL, Cates CJ, Li A, Kynaston JA, Turner C, Chang AB. Tailored interventions based on exhaled nitric oxide versus clinical symptoms for asthma in children and adults. Cochrane Database Syst Rev. 2009;4:CD006340. 
71. Lu M, Wu B, Che D, Qiao R, Gu H. FeNO and asthma treatment in children: a systematic review and meta-analysis. Medicine (Baltimore). 2015;94(4):e347.

72. Nolte H, Pavord I, Backer V, et al. Dose-dependent anti-inflammatory effect of inhaled mometasone furoate/formoterol in subjects with asthma. Respir Med. 2013;107:656-64.

73. Knoery C, Brockway B, Cowan J, Cox E, Taylor R. Non-adherence to inhaled corticosteroid therapy as an explanation for persistently elevated exhaled nitric oxide levels in patients with asthma; effect of directly observed therapy with inhaled corticosteroids. Eur Resp J. 2015;46(Suppl):59. doi:10.1183/13993003.congress-2015.PA3999.

74. Katsara M, Donnelly D, Iqbal S, Elliott T, Everard ML. Relationship between exhaled nitric oxide levels and compliance with inhaled corticosteroids in asthmatic children. Respir Med. 2006;100:1512-7.

75. Koster ES, Raaijmakers JAM, Vijverberg SJH, Maitland-van der Zee A-H. Inhaled corticosteroid adherence in paediatric patients: the PACMAN cohort study. Pharmacoepidemiol Drug Saf. 2011;20:1064-72.

76. Thomas M, Taylor DR. Assessing inflammatory phenotypes and improving cost-effectiveness of asthma and COPD care in the community. Prim Care Respir J. 2011;20:349-50.

77. Pérez-de-Llano LA, Carballada F, Castro AO, et al. Exhaled nitric oxide predicts control in patients with difficult-to-treat asthma. Eur Respir J. 2010;25:1221-7.

78. Maslow AH. The changing image of human nature. The psychological aspect. Desacralization. Am J Psychoanal. 1966;26:148-57.
79. Brand PL, Baraldi E, Bisgaard H, et al. Definition, assessment and treatment of wheezing disorders in preschool children: an evidence-based approach. Eur Respir J. 2008;32:1096-110.

80. Brand PL, Caudri D, Eber E, et al. Classification and pharmacological treatment of preschool wheezing: changes since 2008. Eur Respir J. 2014;43:1172-7.

81. Panickar J, Lakhanpaul M, Lambert PC, et al. Oral prednisolone for preschool children with acute virus-induced wheezing. $\mathrm{N}$ Engl J Med. 2009;360:329-38.

82. Nwokoro C, Pandya H, Turner S, et al. Intermittent montelukast in children aged 10 months to 5 years with wheeze (WAIT trial): a multicenter, randomized, placebo-controlled trial. Lancet Respir Med. 2014;2:796-803.

83. Cane RS, Ranganathan SC, McKenzie SA. What do parents of wheezy children understand by "wheeze"? Arch Dis Child. 2000;82:327-32.

84. Moeller A, Diefenbacher C, Lehmann A, et al. Exhaled nitric oxide distinguishes between subgroups of preschool children with respiratory symptoms. J Allergy Clin Immunol. 2008;121:705-9.

85. Singer F, Luchsinger I, Inci D, et al. Exhaled nitric oxide in symptomatic children at preschool age predicts later asthma. Allergy. 2013;68:531-8.

86. Brouwer AF, Roorda RJ, Brand PL. Home spirometry and asthma severity in children. Eur Respir J. 2006;28:1131-7.

87. Wensley D, Silverman M. Peak flow monitoring for guided self-management in childhood asthma: a randomized controlled trial. Am J Respir Crit Care Med. 2004;170:606-12. 